\title{
Development of a 3D groundwater model based on scarce data: the Wadi Kafrein catchment/Jordan
}

\author{
Yajie Wu • Wenqing Wang • Mathias Toll • \\ William Alkhoury • Martin Sauter • \\ Olaf Kolditz
}

Received: 17 January 2010/ Accepted: 19 December 2010/Published online: 8 January 2011

(C) Springer-Verlag 2011

\begin{abstract}
In this work, a 3D groundwater flow model integrating all important geological features of the hydrogeological system is developed to investigate hydrological processes in the Wadi Kafrein area of Jordan. A large amount of available geological and hydrological data is integrated to construct a 3D groundwater flow model for the Wadi Kafrein area. Using the newly developed mapping approach, the translation of the highly detailed geological formations to an unstructured finite element grids, can be accomplished with high precision. The existing data set for model calibration is scarce, which is a typical situation for many hydrogeological case studies. At first, the steady state calibration of the groundwater model is carried out based on the observation wells. Then, the time and space-dependent recharge from precipitation are applied at the top surface of the finite element model. The transient simulation is conducted during the period of 1996-2008 considering the abstraction rates of the production wells
\end{abstract}

Y. Wu $(\bowtie) \cdot$ W. Wang · O. Kolditz

Helmholtz Centre for Environmental Research-UFZ,

Permoserstr. 15, 04318 Leipzig, Germany

e-mail: yajiewu@ouc.edu.cn

O. Kolditz

Dresden University of Technology, Helmholtzstr. 10, 01069 Dresden, Germany

e-mail: olaf.kolditz@ufz.de

M. Toll · W. Alkhoury · M. Sauter

University of Göttingen, Goldschmidtstr. 3,

37077 Göttingen, Germany

Y. Wu

Ocean University of China, 238 Songling Road,

Qingdao 266100, People's Republic of China and discharge of the springs. The calculated water levels are close to the observed values. The difference is partly caused by return flows from irrigation and the groundwater inflow from the adjacent aquifers which are not taken into consideration so far. Since the Wadi Kafrein area is an important agricultural area in the semiarid region of the Lower Jordan Valley, the model developed in this study can be regarded as a useful tool for analyzing the hydrological processes and improving groundwater management practices elsewhere affected by similar geological and hydrogeological conditions.

Keywords Wadi Kafrein · Groundwater modelling · Model calibration · Arid and semiarid areas

\section{Introduction}

Groundwater resources in Jordan are limited due to semiarid to arid climatic conditions. The present impacts on the groundwater are manifested in the drop in groundwater levels, considerable decrease in spring discharges, saltwater intrusions and deteriorating water quality (Salameh 2008). In the Wadi Kafrein area, groundwater resources are the major source of water supply for domestic and agricultural purposes. In order to achieve sustainable exploitation of groundwater resources and to quantify the impact of climate change on water resources, a proper understanding of the behaviour of the groundwater system and assessment of the groundwater resources is an important prerequisite.

Numerical modelling of groundwater flow has become an invaluable tool for proper management of the groundwater systems (Istok 1989), especially for the assessment of the impact of existing and proposed activities on 
groundwater resources (e.g. Salameh and Hammouri 2008; e.g. Huang et al. 2008; e.g. Wang et al. 2008). A literature survey of groundwater research in the Jordan Valley revealed that different groundwater flow models have been developed and applied to resolve different groundwater flow problems. Several researchers, e.g. Abu-Jaber and Ismail (2003), Siebert et al. (2005), Khayat et al. (2009) analysed potential recharge sources to the shallow aquifer system by a geochemical mass-balance approach to understand the reasons for the rapid degradation and salinization of the shallow aquifer in the northern Jordan Valley. Beinhorn et al. (2004) developed a hydrological model of the shallow aquifer in the Jericho Area and the model was verified to some extent using time series of chloride concentration contours. Al-Abed et al. (2005) used the Spatial Water Budget Model (SWBM) and HECHMS / HEC-GeoHMS extension model to investigate the Zarqa River basin in western Jordan, with the aims of exploring the advantages of using GIS-based hydrological models as a water management tool. Werz (2006) developed and tested the integrated use of a GIS data and remote sensing imagery for the assessment and the mapping of groundwater vulnerability, groundwater hazards and groundwater risk intensity, to improve the data situation in the Wadi Shueib, Jordan and to investigate to what extent conventional procedures of data acquisition can be enhanced by information extracted from remote sensing imagery. Groundwater vulnerability, hazards, and risk intensity were mapped (scale 1:50,000) at a test site near the Jordan Rift Valley (Werz and Hötzl 2007). The resulting maps indicate clearly the vulnerable areas and the "hot spots" of potential contamination in the test site. Toll (2008) proposed an integrated approach for the provision of a reliable database based on the sparse and fuzzy data for the unconsolidated valley fill aquifer of the Jordan Valley. The water balance was calculated on the basis of historical data combined with remote sensing techniques and thus a steady-state numerical flow model could be generated. Odeh et al. (2009) conducted a hydrogeological study of a sub-catchment of the Zerka River drainage basin using remote sensing, GIS, and field methods. The results indicated that the structures in the study area have major effects on the groundwater flow regime. The anticlinal setting of the study area diverts the groundwater towards the southwest, carrying dissolved cations and anions and causing their concentrations to increase in that direction. Ta'any et al. (2009) studied spatially and temporally variable groundwater level fluctuations of the upper aquifer in the Amman-Zarqa basin over the period of 2001-2005, using geostatistical and kriging techniques. More groundwater research work concerning the Jordan Valley can be found in the book by Hötzl et al. (2009). However, these studies were carried out based on a wealth of geological and hydrogeological data and concentrated only on the shallow aquifer system or the upper aquifer of the study area.

The present study is concerned with the development of a 3D groundwater model to represent the groundwater flow system and the groundwater levels in the Wadi Kafrein area, based on all available geological and geophysical data set together with several field surveys. The challenge in this work is to apply a numerical flow model to the steep and complex geological layers. Due to its proximity to the active plate boundary, the geology of the study area is rather complex. The numerical model is implemented in the framework of the open source scientific software OpenGeoSys (OGS) and new functionalities are added into the code in order to meet the challenges. The 3D finite element mesh of the study area is constructed using a newly developed mapping approach considering the complex geometry of subsurface strata. With the obtained high resolution mesh, the steady-state groundwater model is then attained by applying appropriate boundary conditions, annual-averaged infiltration and hydrogeological parameters, and it is calibrated using the available data from observation wells. Then, the time-dependent source/sink terms are imposed on the top surface of the domain and a transient model is developed. Finally, the comparisons of calculated versus measured groundwater levels are also carried out. The present model in this work could be transferred to the other regions with comparable geological and hydrological conditions.

\section{Description of the study area}

Wadi Kafrein is one of the three major wadis (Wadi Shueib, Wadi Kafrein and Wadi Hisban) which incise deeply into the Western Slopes of the East Bank of the Jordan River northeast of the Dead Sea. The study area (the subsurface catchment of Wadi Kafrein), is located in the lower Jordan Valley and belongs geographically to the Eastern Mediterranean Basin (Fig. 1). The centre of the study area is located at WGS84 coordinates $31^{\circ} 55^{\prime} \mathrm{N}$ and $35^{\circ} 46^{\prime} \mathrm{E}$ with a total area of about $189 \mathrm{~km}^{2}$ (Ali et al. 1999). The maximum extension of the study area is $19 \mathrm{~km}$ in east-west and around $24 \mathrm{~km}$ in north-south direction. The highest point in the study area is located on the eastern border, the western part of Sweileh city with an elevation of $+1,096 \mathrm{~m} \mathrm{msl}$. The lowest point is located on the west of the study area, next to a large surface water reservoir (Wadi Kafrein Dam) at an elevation of $-190 \mathrm{~m}$ msl (Toll et al. 2009). Wadi Kafrein Dam was built at the head of the wadi opening towards the Jordan Valley. The reservoir capacity amounted to $3.8 \mathrm{Mm}^{3}$ (million cubic meter) at first, later the dam was raised up to a capacity of $8 \mathrm{Mm}^{3}$ (Ali et al. 2009). 
Fig. 1 Location of a the Middle East $\mathbf{b}$ study area in the regional context $\mathbf{c}$ the surface water catchment boundaries of Wadi Kafrein and Wadi Shueib are highlighted by a white line (Toll et al. 2009)
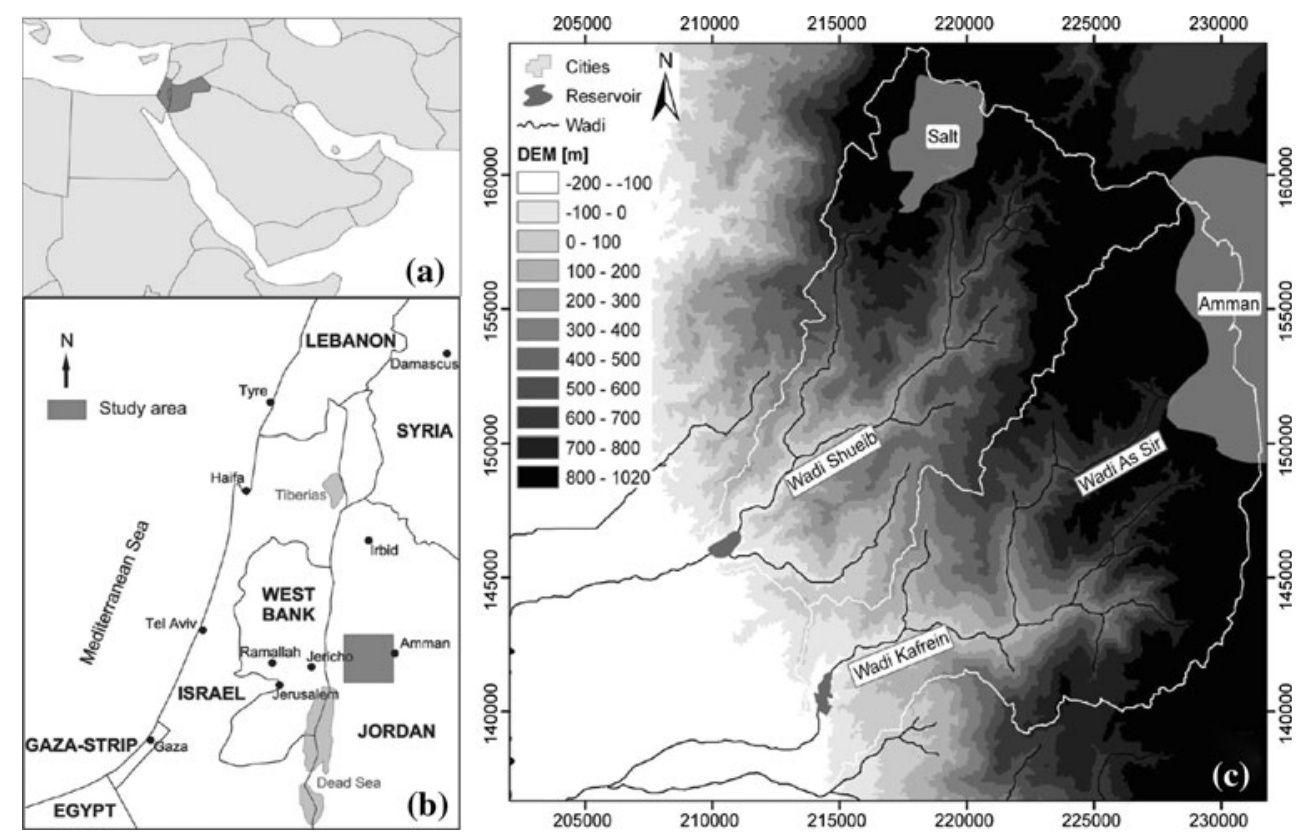

\section{Precipitation}

According to Köppen (1931), the study area can be classified as a Group B Dry (arid and semiarid) climate since precipitation is less than the potential evaporation. Since morphology has the largest influence on the prevailing climate, a subdivision into three different climatic zones can be made: the highlands area, the Western Slopes of the East Bank, and the Jordan Valley. The climate in the highlands is of Mediterranean type. It is characterized by long, hot, dry summers and short, cool, rainy winters. Towards the west, the climate undergoes a rapid change to semi-arid and arid climate in the Jordan Valley. The western slopes act as a transition zone between the Mediterranean climate along the highlands in the east and the arid climate in the Jordan Valley in the west (Toll et al. 2009).

As the other wadis, Wadi Kafrein does not show perennial flow evidence. However, during and after the rainy events, they also drain floodwater down to the Jordan Valley. The floodwater carries sediments and sometimes even rocks forming fan deposits in the Jordan Valley. Rain falls only during the winter months. Then, the climate changes abruptly from dry hot summer conditions to humid, cold, and stormy conditions. Usually it starts to rain in November and rainfall continues until the end of April, whereby $70 \%$ of the annual precipitation falls between November and February. In the highlands, precipitation may occur as snow falls once or twice a year but usually as rain (Salameh and Bannayan 1993). The long-term average rainfall in the catchment area of Wadi Kafrein is 410 mm/year (Salzgitter and JCE, 1993). The average annual precipitation on the western ridges of the highlands is around $505 \mathrm{~mm} /$ year, on the eastern part of the Western slopes $395 \mathrm{~mm} / \mathrm{year}$, and in Jordan Valley the long-term average is around $166 \mathrm{~mm} /$ year. Thus, a strong correlation with altitude and climate data for the area exists (Toll et al. 2009).

\section{Aquifer system}

The study area is a multi-aquifer system that includes regional aquifers which are located in the mountainous area and downstream (Fig. 2). In the foothills, they are laterally connected to alluvium aquifers extending in the subsurface of the Jordan Valley (Guttman et al. 2009).

From the geological perspective, three unconsolidated groups exist in the study area. The Lower Cretaceous Kurnub Group overlies the early Cretaceous transgressive unconformity along the margins of the rift valley. The most important regional aquifer in the highlands is located in the Ajlun Group. Several case studies demonstrated that this aquifer is divided into the upper and the lower sub-aquifers (Guttman 2000). The Shueib Formation is composed of calcareous siltstone, mudstones and shales which act as aquiclude separating between the two sub-aquifers (Guttman 2009): i.e. a lower sub-aquifer in the Hummar Formation and an important upper sub-aquifer formed by the Wadi as Sir Formation together with the basal Belqa Group. The lower part of the Ajlun Group, the Na'urFuheis Formations, forms an aquiclude which separate this aquiferous sequence from the underlying sandstone aquifer. The detailed description of the above-mentioned Formations can be found in the PhD dissertation (Toll 2007). 


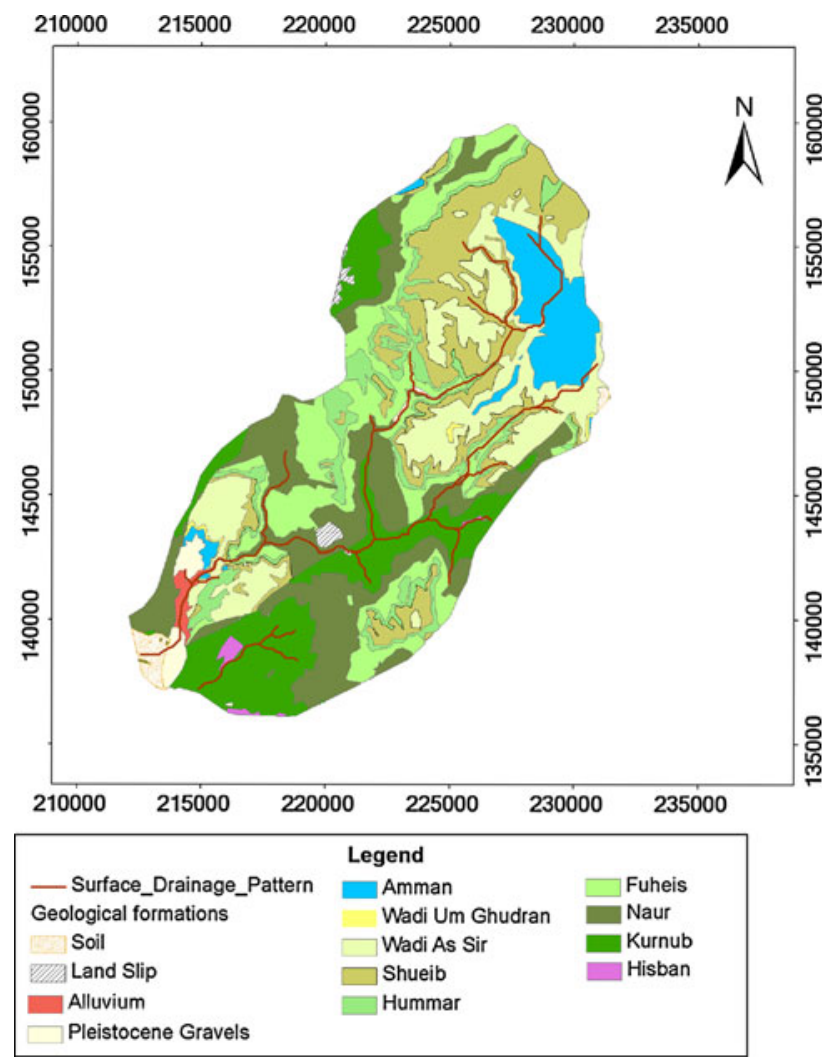

Fig. 2 Geological map of the study area [compiled from Shawabkeh (2001)]

\section{Groundwater abstraction}

Data on groundwater abstraction are available from the local water authorities. The production data of four wells located in the southwest part of the study area near the Jordan Valley is available in part of the simulated period (locations of the production wells, see Fig. 3). All production wells are in the Kurnub aquifer except one is in the Na'ur aquifer. These wells pump groundwater from the Kurnub aquifer or the young sediments in the subsurface of the Jordan Valley. Their discharge is in the order of some tens of $\mathrm{m}^{3} / \mathrm{h}$. Generally speaking, the young sediments in the Jordan Valley are naturally replenished by water from different sources such as lateral flows from the surrounding mountain aquifers, infiltration of direct precipitation and percolation of flood water runoff, return flows from irrigation, and ascending of saline water from deep-seated aquifers. Therefore, the groundwater of the young sediments in the Jordan Valley contains saline water to some extent. As the result of pumping, the water level has dropped and the saline water flow towards the pumping wells that consequently increase the salinity of the water (Guttman 2009).

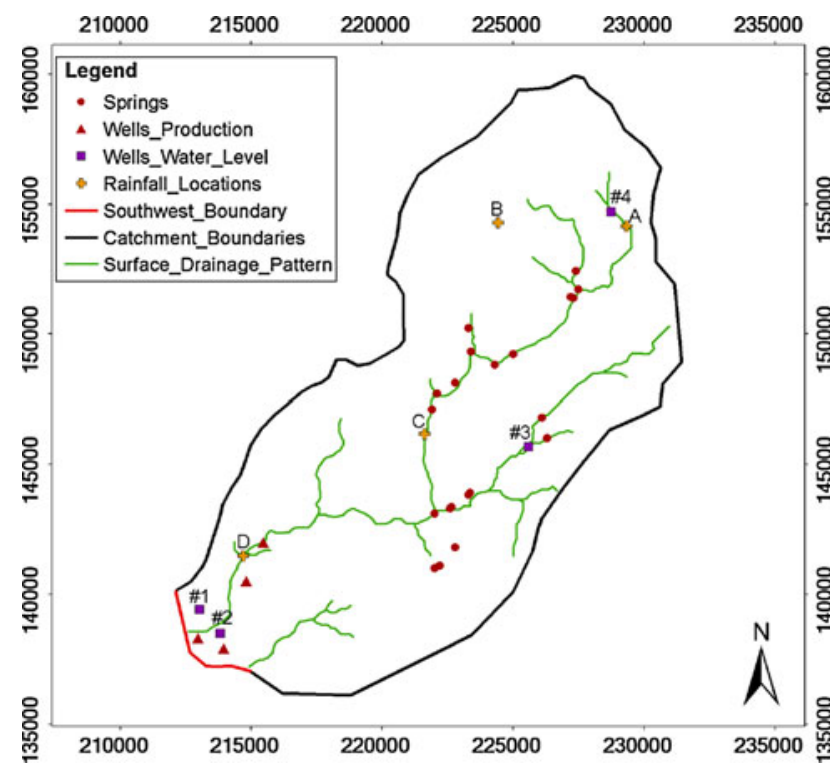

Fig. 3 Wells, springs and boundary conditions in the groundwater model (compiled using the data from the Ministry of Water and Irrigation of Jordan)

\section{Springs}

In the study area, springs are also an important source for drinking water and irrigation. Most of the springs are located along the intermediate reaches of the Kafrein (locations of the springs, see Fig. 3). They discharge from the lower Kurnub Group, from the Naur formation, from the lower sub-aquifer and from the upper sub-aquifer. The discharge of the springs ranges from a few cubic meters to a few hundred cubic meters per hour. The data from 1980 to 2006 indicate that, even though some springs are located very close to each other, there is large difference in amount of discharge between each other. For example, the average per hour discharge of one spring is ca. $380 \mathrm{~m}^{3} / \mathrm{h}$, whereas in its nearest neighbor, the discharge is only ca. $80 \mathrm{~m}^{3} / \mathrm{h}$. The discharges of these springs are all taken into account in the following transient groundwater model.

\section{Model development and implementation}

A considerable amount of input data is required to construct and verify a regional distribution model of the groundwater flow. However, a computational model that aims to simulate groundwater processes in such an area generally has to deal with the problem of considerable lack of information. Nevertheless, groundwater flow and transport model of the neighbouring area have been successfully developed as described in the introduction, such as the northern Jordan Valley (Abu-Jaber and Ismail 2003), the 
Jericho area (Beinhorn et al. 2004), the Lower Jordan Valley/Jordan (Toll 2008), the Zarqa River basin (Al-Abed et al. 2005; Odeh et al. 2009), and Amman-Zarqa basin (Ta'any et al. 2009).

In this work, OpenGeoSys scientific modelling software is used for the development of the numerical groundwater flow model for the Wadi Kafrein area. OGS is programmed in $\mathrm{C}++$ according to the object-oriented software concepts, and it can be used to simulate flow, mass, heat transport and deformation as well as chemical reaction processes in porous and fractured media (Miles et al. 2007; Park et al. 2008; Wang et al. 2009). The implementation of numerical methods involving geometric description of geosystems with the application of finite element analysis is of vital importance for investigation and modelling of complex coupled nature or man-induced processes. The main concept of OGS is to encapsulate the geometry, the mesh and physical data, and the corresponding methods into different objects. More important, the object-oriented programming allows an easy extension of the code to more complex applications (Kolditz et al. 2008). The capability of OGS in groundwater flow and transport simulations has been verified against a large number of benchmarks, e.g. the classical seawater intrusion problem of Henry, the free convection problem by Elder and the salt dome problem (Segol et al. 1975; Kolditz and Diersch 1993; Beinhorn et al. 2005).

\section{Conceptual flow model}

In the study area, groundwater flow is structurally determined and it flows from the northeast down to the Jordan Valley in the southwest. However, in the vicinity of the drainage areas, groundwater is redirected toward the wadis. The predominant elements governing the geological structure and flow regime are the NNE-trending Kafrein normal fault and associated fault bounding the Kafrein syncline to the West, and the Kafrein asymmetric syncline. Wadi Kafrein follows synclines and flows down the western slopes of the Transjordanian Mountains toward the Jordan Valley depression (Toll 2007). From the view point of water budget, the major inflow terms are the vertical recharge from precipitation on the outcrops in the eastern highlands and the major outflow terms are pumping abstraction, spring discharge and lateral discharge across the southwest boundary.

The origin of the water in the different sandstone aquifers is still not very clear. Direct recharge into the Kurnub aquifer is restricted to its outcrops along the lower parts of the slopes in Wadi Kafrein. The wadis are not only collecting the surface runoff, especially the flash floods during the winter seasons, but also the groundwater flow which is discharging through springs near the wadis. At present, the wadis also carry more and more effluents from waste water treatment plants. Groundwater finally flows into the alluvial fans at the foothills. The unconsolidated alluvial aquifers eventually discharge either towards the Dead Sea, the river Jordan or saline evaporation ponds. The outlet of Wadi Kafrein serves as an example for such outflows through wadis. More details about the shallow alluvial aquifer located in the downstream of Wadi Kafrein Reservoir are available from e.g. Ali et al. (2009).

\section{D structural model}

The implementation of geometrical description of geosystems with the application of numerical meshes is of vital importance for modelling the aquifer systems and the groundwater flow (Kalbacher et al. 2005; Rodiger et al. 2009). The construction of the 3D structural model for the wadi area is a challenge because of the complex geometry of subsurface strata. The general procedure of developing the 3D structural model is as follows (Fig. 4):

\section{GIS data}

All required GIS data for modelling is converted to the appropriate formats for numerical modelling using the commercial ArcGIS 9.3 software package (ESRI Inc.). The subsurface catchment and the flow path (Fig. 5) are saved as shape files, which serve as the geometric boundary of the modeled area and the source terms (i.e. infiltration) assigning, separately. However, the Digital elevation model (DEM) of the study area (Fig. 5) and the geological features of layers (Fig. 6) for the study domain need to be converted for the mapping purpose. It can be seen from Fig. 6 that there are empty domains existing in most of the hydrological layers, which are the outcrop areas of the Kurnub Group. The existence of these outcrop areas raises much more difficulty in creating the 3D finite element mesh based on layers information. At first, the shape files are imported into OGS. Then, the geometric objects including points, polylines and surfaces are created and saved in a (gli) file. Based on the geometric objects (e.g. domain boundary), a finite element mesh has to be created at the next step.

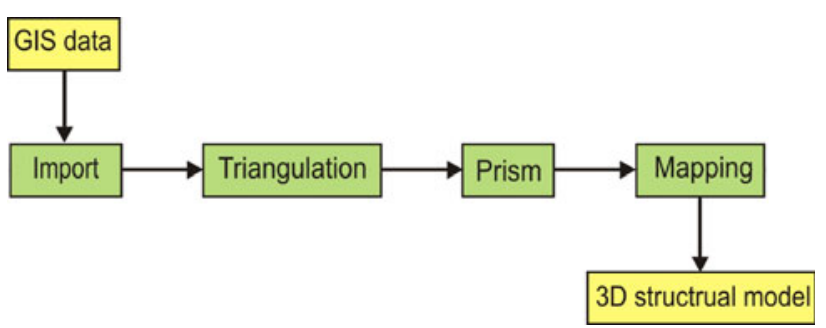

Fig. 4 The workflow of creating the 3D structural model 


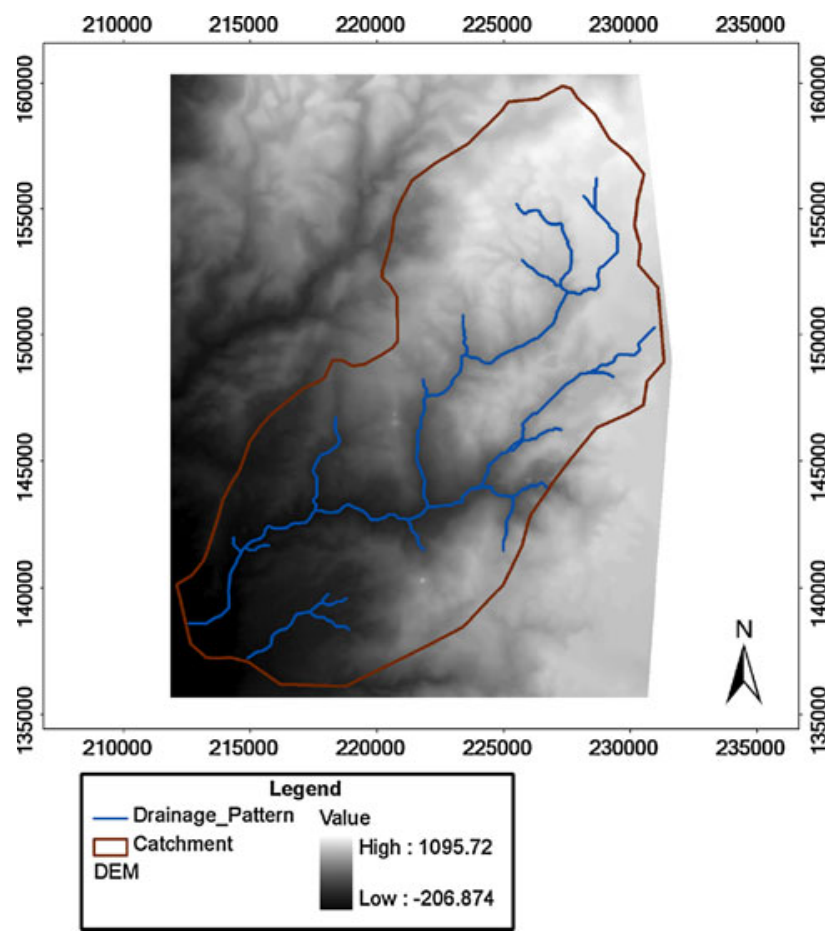

Fig. 5 Digital elevation model, subsurface catchment and the drainage network of the Wadi Kafrein area

\section{Triangulations and prisms}

Based on the surface created from the subsurface catchment domain, triangulation is carried out to obtain the $2 \mathrm{D}$ mesh of the vertical project area of the domain (Fig. 7).
The most important for this step is to have dense elements along the drainage line of the different surface wadis, which represents episodic streams in the study area. The mesh density varies from $300 \mathrm{~m}$ in the vicinity of the wadis and $500 \mathrm{~m}$ at the other areas. Prismatic elements are generated from $2 \mathrm{D}$ triangular mesh by specifying the number of layers and layer thickness. In the study area, the geological formations are divided into eight hydrological units. Accordingly, prismatic elements for eight layers are created and layer topography can be changed after using mapping techniques.

\section{Mapping}

The most demanding procedure is surface mapping. It is the process of making the mesh conform to stratigraphic irregularities, i.e. thickness and orientation of the mesh slices can be deformed (Chen et al. 2005). It is also the basis for creating a successful 3D mesh for the subsurface model.

As mentioned above, when raster data is converted into an ASCII file, some areas are marked with NODATA for elevation, which represents a discontinuity of a layer or out of range of the study domain. The original mapping function designed to deal with continuously data does not work for such complex geological formations. Therefore, the mesh elements including NODATA points should be deleted directly from the layers, because they do not exist in reality. The detailed description of the mapping implementation method is described below.

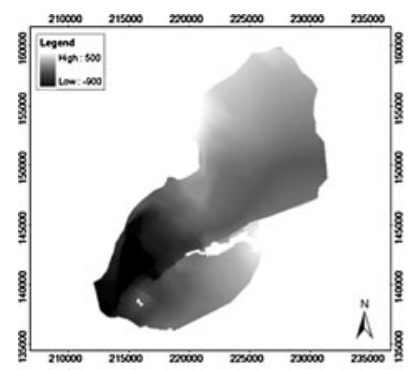

(a)

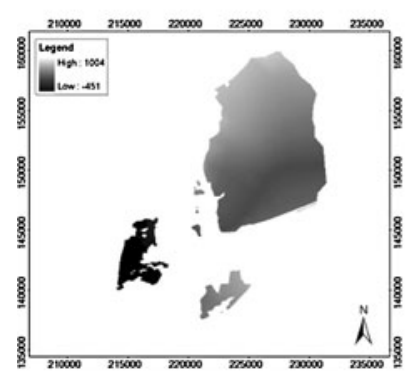

(e)

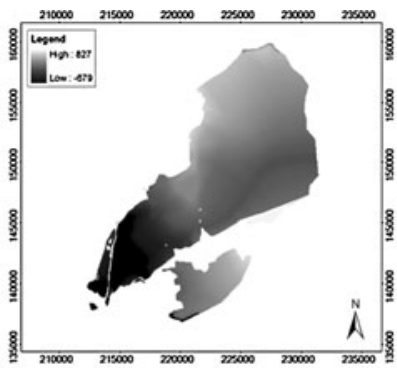

(b)

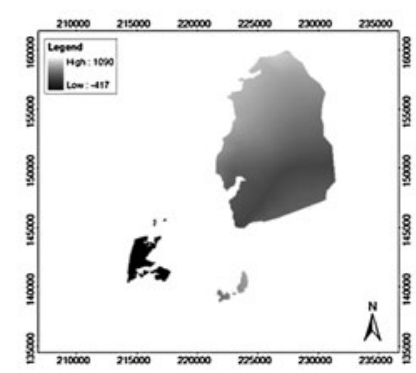

(f)

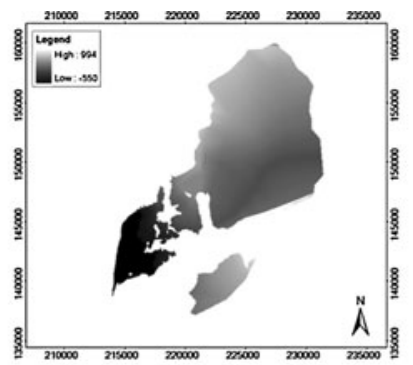

(c)

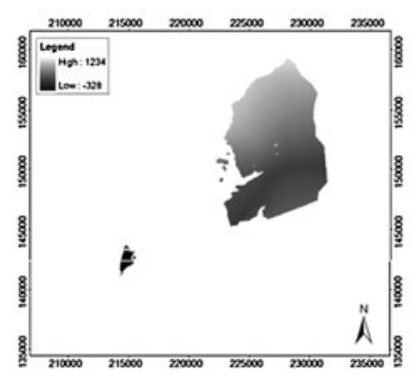

(g)

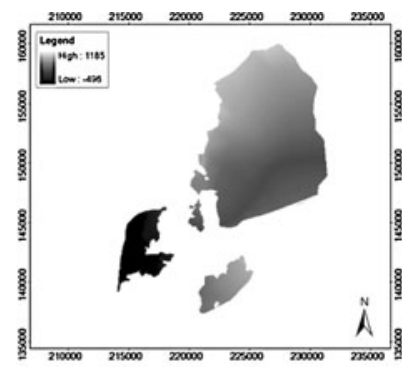

(d)

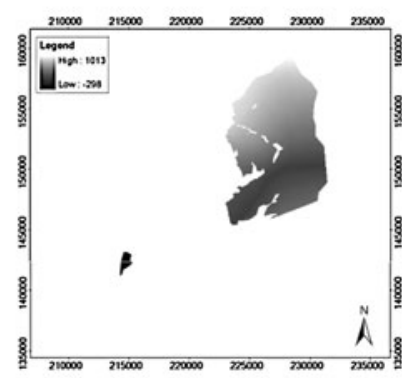

(h)

Fig. 6 The geological features of eight hydrological units (from lowermost to upmost, i.e. from bottom to top) 


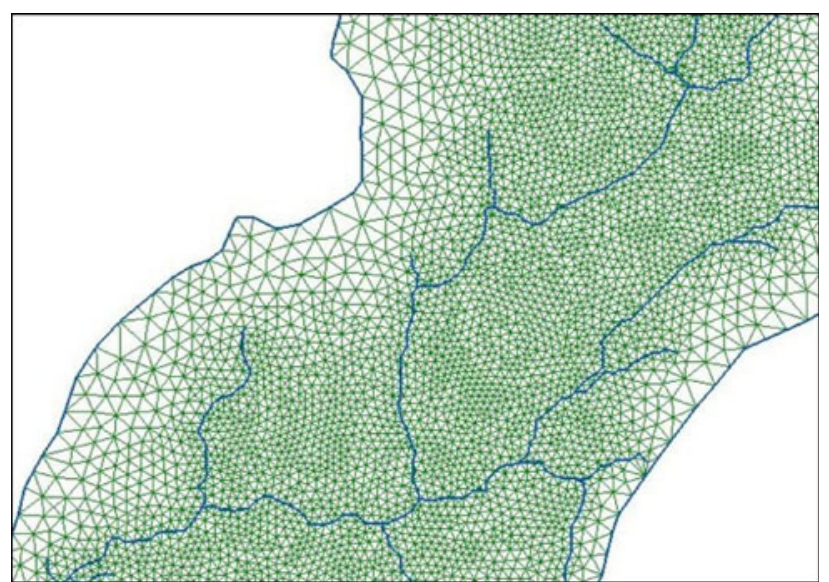

Fig. 7 The 2D triangular mesh of the Wadi Kafrein area

Firstly, mapping is processed using the original mapping function as usual. The elevations of nodes are interpolated from the raster data. In this step, the nodes are divided into two categories, the normal nodes and the NODATA nodes. The corresponding nodes are marked with a flag of true and false, respectively. As for the former, four raster points around it are all normal elevation values. The latter is the nodes that at least one raster point around it is a NODATA point.

Secondly, a special process of elements is performed to check, remove and adjust involved elements including NODATA nodes. This is the most important part to obtain accurate mapping result.

1. Node reassigning: It is assumed that all base layer data on the inside of the catchment exists. Beginning the loop from the bottom layer to surface layer, when the node flag is detected as false, the value is replaced with the elevation of the layers under it. This is based on the fact that the elevation of all nodes are referencing the same zero surface.

2. Element checking, removing and adjusting: After checking every element layer by layer, four different measures are taken to process these elements according to the number of the nodes that need to be deleted in a single element. Within the mesh construction process, the computational actions on elements can be categorized into the following types:

(a) Normal element. No change is required.

(b) One node needs to be deleted. The old prism element is chopped into tetrahedral elements.

(c) Two nodes need to be deleted. The old prismatic element is converted into a tetrahedron element.

(d) Three nodes need to be deleted. The old prismatic element is removed. The exception of this type is that the nodes values of vertical counterparts are not existed in other layers except for the bottom layer and the surface layer. The elements including such type of nodes need to be processed very carefully.

Finally, topology of mesh is re-established based on the above removal and adjustment.

After this procedure, the eight layers are mapped to the corresponding elevation and a hybrid mesh of 24,115 elements (3,772 tetrahedral elements and 20,343 prismatic elements) with 13,390 nodes is generated based on the new approach for elements removal and adjustment. The structural model incorporates all important geological features, such as channels, folds and thickness variations of the different geological strata. As a result, a mesh file is created containing node geometry and element topology as well as the material group connected with the elements. This mesh file will be used as input file later on for the simulations of groundwater flow. Mapping results of every material group from bottom to top are shown in Fig. 8 . Note that the $X$ and $Y$ axes represent the east direction and the north direction, respectively, which is the same for the following figures in this work. By comparing Fig. 6 with Fig. 8 , it can be clearly seen that the 3D structural model created using the new method shows good agreement with the geological features of layers. The whole mesh and a selected typical cross section are also depicted in Fig. 9 to show the relations of hydrogeological layers. The new mapping approach enabled the complex structural details of the geological formations to be accurately reproduced in the numerical model domain, i.e. the finite element mesh.

3D groundwater flow model

\section{Governing equations}

The governing equations for 3D groundwater flow are based on water mass balance and Darcy's law (e.g. Bear 1972):

$S_{s} \frac{\partial h}{\partial t}-\left[\frac{\partial}{\partial x}\left(\mathbf{K}_{x} \frac{\partial h}{\partial x}\right)+\frac{\partial}{\partial y}\left(\mathbf{K}_{y} \frac{\partial h}{\partial y}\right)+\frac{\partial}{\partial z}\left(\mathbf{K}_{z} \frac{\partial h}{\partial z}\right)\right]=\mathbf{q}_{s}$

where $h$ is the hydraulic head, $S_{\mathrm{s}}$ is the specific storage, $\mathbf{q}_{\mathrm{s}}$ is a sink or source, and $\mathbf{K}_{x}, \mathbf{K}_{y}, \mathbf{K}_{z}$ is the hydraulic conductivity in $x, y, z$ directions, respectively. In the study area, the governing Eq. (1), together with the boundary conditions, the initial conditions, the spatial distribution of the hydrogeological parameters that control the flow, constitutes the mathematical model of the groundwater flow (Freeze and Cherry 1979). 
Fig. 8 Mapping results of every material group (from bottom to top)
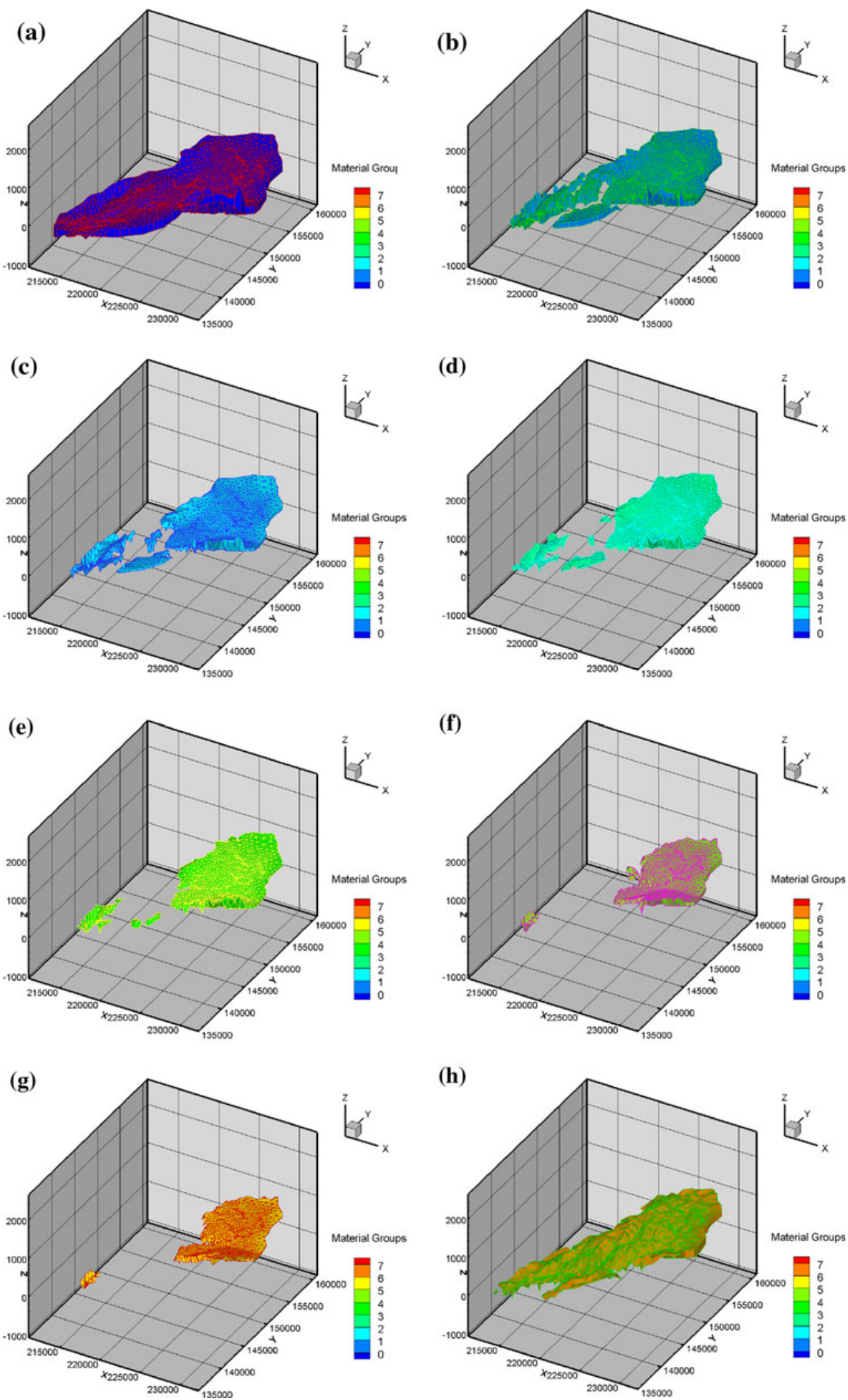
Fig. 9 a Mapping result of the whole domain b hydrogeological formations on cross section $A-A^{\prime}$
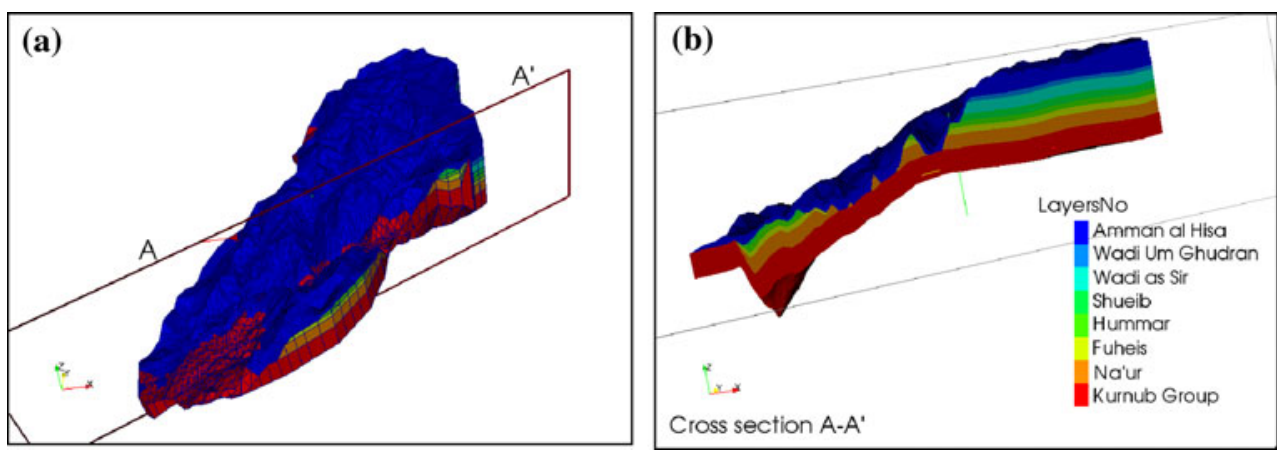

\section{Boundary conditions}

According to the basic hydrogeological information, the following boundary conditions are set in the steady state groundwater model. Fixed-head boundary conditions are applied to the northeast boundary and the southwest boundary, and no-flow boundary conditions are set to other part of the catchment borders (see Fig. 3). The adjustment in boundary conditions is performed during the model calibration procedure in order to achieve the best match between the calculated and the observed groundwater levels from the observation wells, as described in the subsequent steady state calibration section.

For the transient model, the variable hydraulic heads are assigned to all nodes of the southwest boundary due to the lack of the real quantities of the outflow flux from the southwest boundary. Based on the head gradient of the nearest observation well \#1, all nodes of the southwest boundary are defined as constants during any given time step, but vary during each successive step. In addition, noflow boundary conditions are prescribed at the northeast boundary.

\section{Source/sink terms}

Usually, source/sink terms of the hydrological system are defined by the recharge from infiltration and discharge (i.e. wells and springs as previously stated) to or from the study area. In the transient model, the abstraction rates of the production wells and discharge of the springs are assigned to the corresponding mesh nodes.

There are 13 stations in the wider area of Wadi Kafrein, but only three of them are inside the subsurface catchment. Since rainfall was sparsely recorded in the study area, it is a complementary measure to use secondary attributes that are more densely measured. Considering elevation is the most widely used additional information in the geostatistical analysis of precipitation distribution (Chua and Bras 1982; Phillips et al. 1992), the multivariate geostatistical method external drift kriging (EDK) is applied to interpolate the rainfall distributions in this study and the elevation are used as a covariate (Samaniego et al. 2009). If there is a correlation between climatological rainfall and altitude, it becomes logical that the inclusion of topographic information should improve the estimates. Pardo-Iquzquiza (1998) used three different geostatistical approaches (ordinary kriging, cokriging and EDK) as estimators of the areal average climatological rainfall mean. In the present case study, EDK seems to give the most coherent results in accordance with the cross-validation statistics.

Firstly, the data of the scattered 13 stations are preprocessed for interpolation. Then, the daily rainfall distributions are obtained using EDK method. Finally, the monthly rainfall distributions are calculated from the interpolated daily results. The recharge of different areas varies widely, depending on rainfall distribution, topographical situation, soil cover, karstification, etc. However, it is difficult to establish a precise regional distribution of the recharge rates, since the related data are scarce and incomplete. As an alternative, the recharge to the aquifers by infiltration of surface water is modelled as an estimated recharge rate of the rainfall for all surface nodes in the current model.

\section{Hydrogeological parameters}

In addition, material properties have to be specified separately for fluids, solids and the porous medium (i.e. the aquifers and aquitards). The specific storage values of the porous medium are assumed to correspond to the storativity coefficient from hydrogeological units and layers thickness. As for the hydraulic conductivity (K), limited pumping test data are available for the study area. Based on the drawdown curves of the three newly drilled wells during the period of October-December 2001 in the upstream of the Kafrein dam, calculated hydraulic parameters for the wells in Wadi Kafrein agree with the value of $3.0 \times 10^{-5} \mathrm{~m} / \mathrm{s}$ published for the Kurnub sandstone (Margane et al. 2002). Due to the limited information, the available data do not allow to obtain a detailed resolution of different conductivity zones. The hydrogeological units and their characteristics applied for the simulations, which 
are compiled from Margane et al. (2002), are given in Table 1.

\section{Results and discussions}

The calibration aims at obtaining an optimal fit between the calculated and the measured data, which is also an important measure for the reliability of the operational model. The calibrated model can later on be used to demonstrate impacts on future water abstraction scenarios and possibly the effect of climate change on groundwater resources. The calibration of the current groundwater model involved two sequential steps. At first, the steadystate model representing the state of the aquifer system before water resources development was calibrated using the measured water level data from four observation wells in order to understand the trend of groundwater level in the whole domain. Then, the transient model calibration was accomplished by simulating ground water level changes in response to the variations of the natural recharge quantities due to the rainfall fluctuations from 1996 to 2008, based on the preliminary hydrogeological properties obtained from the steady-state calibration.

The steady state model

The observed water level of four wells is available and they are distributed in different parts of the study area (locations of the observation wells, see Fig. 3). The observation well \#1 and the observation well \#2 are both tapping from the Alluvial aquifer. The observation well \#4 is located in the Na'ur aquifer, according to the reports of WAJ (Water Authority of Jordan). Regarding the observation well \#3, there is no information about it in the records of WAJ. It is not a governmental but a private well in a farm. Due to the data are recorded only non-systematically, accurate and quantitative calibration is difficult. Since the measured water levels vary with time, the averaged values are applied for calibration. Meanwhile, the annual averaged rainfall distributions are applied at the top surface and the recharge rate to the groundwater is assumed as $20 \%$ of the rainfall. To obtain the best match between the calculated and the observed groundwater levels from the observation wells, the necessary adjustment of the boundaries, hydraulic conductivities and specific storage is performed during the model calibration procedure. The fixed-head boundary conditions given at the southwest boundary and

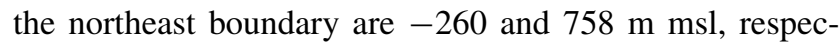
tively. Figure 10 shows a scatter diagram of the observed versus calculated water level in monitoring wells. Obviously, the obtained water levels of the observation wells match very closely with the measured values. The simulation results of the hydraulic heads under steady-state conditions are shown in Fig. 11. It can be seen that the general groundwater flow pattern is clearly represented, i.e. from the highlands area to the Jordan Valley. Therefore, it can be concluded from the comparisons presented here that

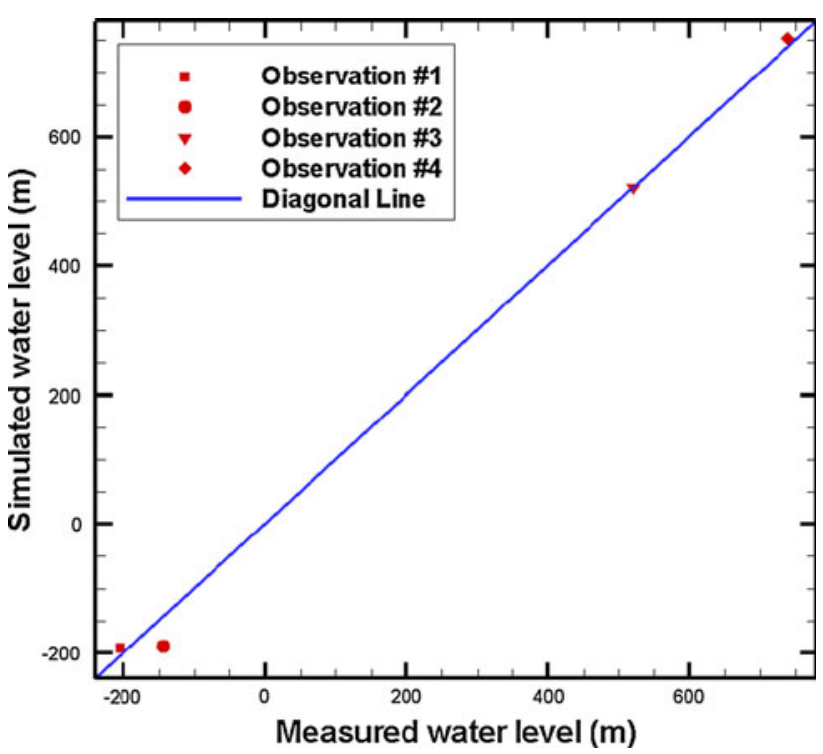

Fig. 10 Observed versus calculated hydrographs at four specific observation wells (see Fig. 3 for locations)
Table 1 The material parameters of the different hydrogeological formations (from top to bottom)

\begin{tabular}{llll}
\hline Formations & $\begin{array}{l}\text { Hydrogeological } \\
\text { unit }\end{array}$ & $\begin{array}{l}\text { Hydraulic } \\
\text { conductivity }\left(\mathrm{ms}^{-1}\right)\end{array}$ & Specific storage \\
\hline Amman al Hisa & Aquifer & $2.0 \times 10^{-6}$ & $1.0 \times 10^{-3}$ \\
Wadi Um Ghudran & Aquifer & $2.0 \times 10^{-6}$ & $1.0 \times 10^{-3}$ \\
Wadi as Sir & Aquifer & $2.0 \times 10^{-6}$ & $1.0 \times 10^{-3}$ \\
Shueib & Aquitard & $1.0 \times 10^{-9}$ & $1.0 \times 10^{-3}$ \\
Hummar & Aquifer & $2.0 \times 10^{-5}$ & $1.0 \times 10^{-3}$ \\
Fuheis & Aquitard & $1.0 \times 10^{-9}$ & $1.0 \times 10^{-3}$ \\
Na'ur & Aquitard/Aquifer & $1.0 \times 10^{-5}$ & $1.0 \times 10^{-3}$ \\
Kurnub Group & Aquifer & $3.0 \times 10^{-5}$ & $1.0 \times 10^{-3}$ \\
\hline
\end{tabular}




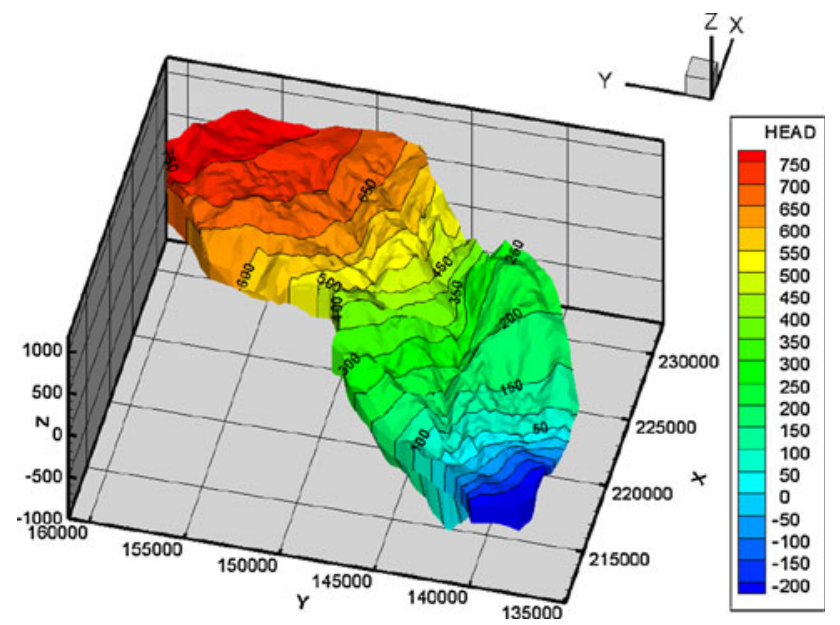

Fig. 11 The contour map of the calculated hydraulic head in the whole domain

the current numerical model provides a fair simulation of the groundwater flow in Wadi Kafrein area.

The transient model

For the transient simulations, the basic geometric set-up and material parameters of the aquifer is the same as that used for the steady state simulations. The resulting flow field of the steady state model is used as the initial condition for the subsequent transient simulations of the flow system in response to the dynamic recharge. The calibration period of time is determined as 13 years from 1996 to 2008 according to the available rainfall data, which is given in the unit of day. In the simulation, the time step size is a natural month of 30 days. Different from the steady state model, time-varying hydraulic heads are applied to all vertical surface of the southwest boundary and no-flow boundary conditions are set at the northeast boundary. In addition, time and space-dependent source terms are imposed on the top surface according to the monthly rainfall interpolated using EDK over the simulation period (see "Source/sink terms"). The most important numerical step is to create the relations between the functions of time-dependent source terms and their corresponding node numbers. The element nodes at the top surface have to be identified taking into account the complexity in the geometry. Analogous to the steady state simulation, the groundwater recharge is assumed as $20 \%$ of the rainfall.

Four locations from different parts of the modeled domain are selected to demonstrate how the rainfall changes over the simulation period (for locations see Fig. 3). It reflects clearly from Fig. 12 that most of the
Fig. 12 Monthly rainfall from 1996-2008 of the scattered points
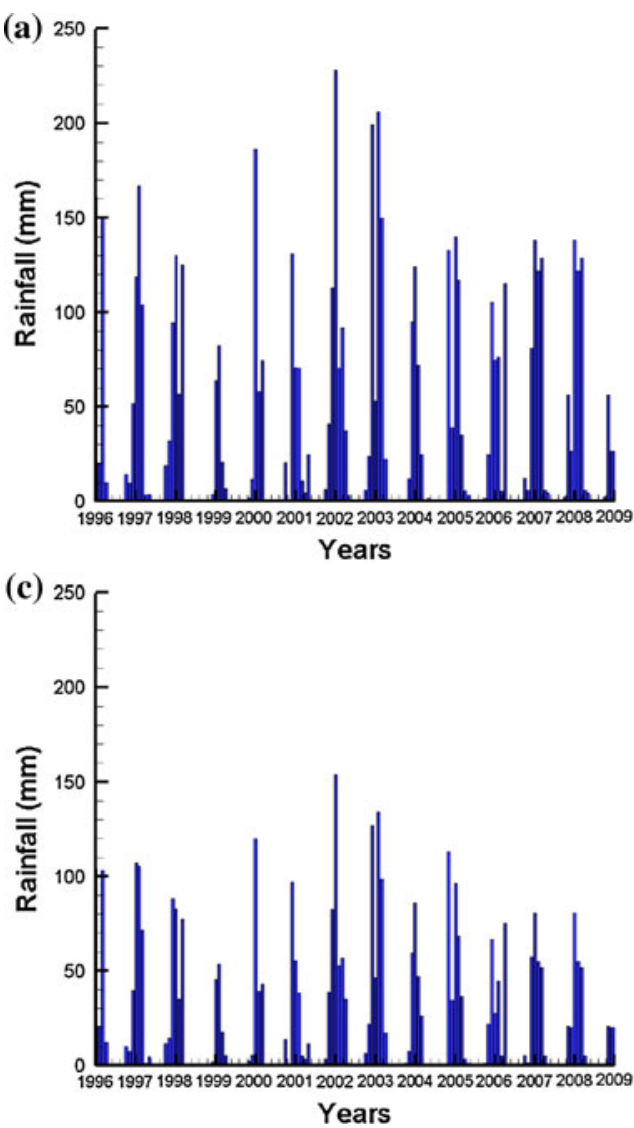
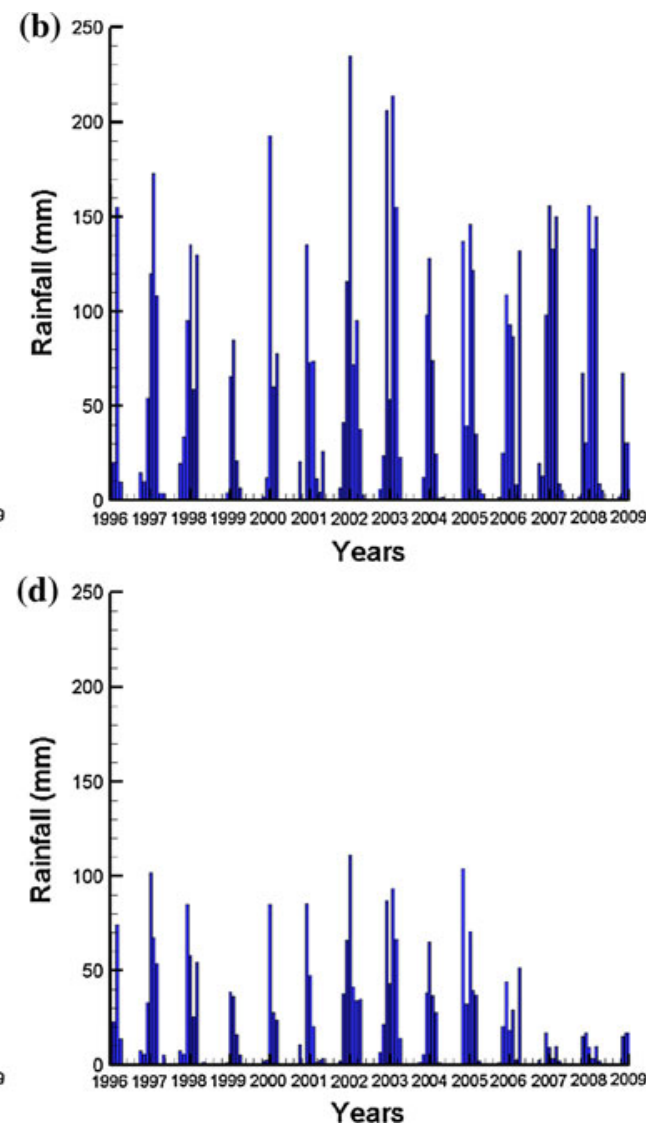


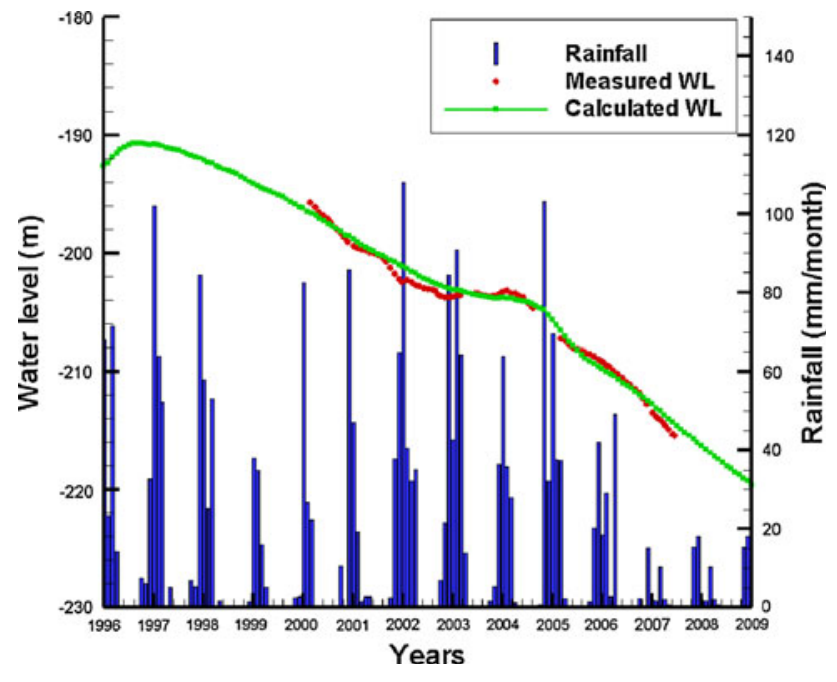

Fig. 13 Calculated versus measured groundwater levels of observation well \#1

rainfall occurs during the rainy season 2001/02 and the least rainfall occurs during the rainy season 1998/99. It is also shown that precipitation occurs in this area only during the winter months as stated in "Precipitation", mostly between November and the end of April. Furthermore, there is a clear pattern of decreasing rainfall towards the Jordan valley.

The transient model calibration is accomplished by simulating hydraulic head changes in response to changes in recharge. With regard to the time series data of water level, only two wells (i.e. observation well \#1 and observation well \#3) have records which cover part of the simulation period. The comparison of calculated versus measured groundwater levels of the two wells, together with their corresponding rainfall curves are shown in Figs. 13, 14. The measured water level in observation well

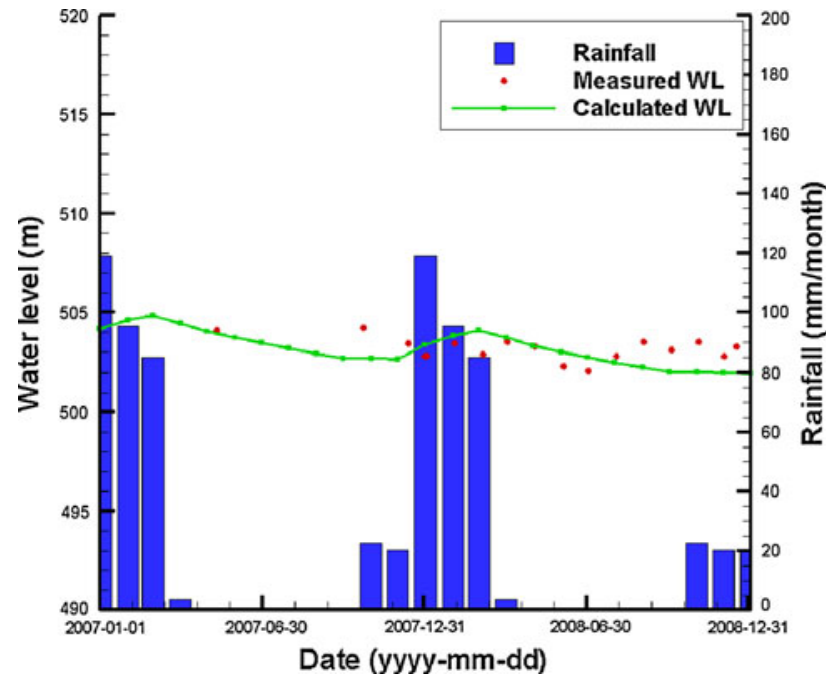

Fig. 14 Calculated versus measured groundwater levels of observation well \#3
\#1 (located near the Jordan Valley, see Fig. 3), indicates that it declines continuously during the recorded period. Figure 13 shows that there is a good agreement between the calculated and the observed groundwater levels in this well. As for observation well \#3, continuous water level is available only for less than 2-year period. Compared to observation well \#1, observation well \#3 is located in the recharge area and has higher average precipitation. The measured groundwater level suggests that it fluctuates seasonally as a direct response to precipitation and flood flows, within a range of around $2 \mathrm{~m}$ during the recorded time (see Fig. 14). The calculated water levels rise during and after the rainy season and drop gradually during summer and autumn. Although the calculated results do not show the frequently fluctuations as the observation data, they both have similar varying magnitude.

Root mean square error (RMSE) is also the most important criteria that used to check the calibration results. Since the calibrated time periods for two wells are different because of the observation data, we could not calculate RMSE using spatially distributed wells. Instead, we could obtain the average difference of the specific well during their own calibrated time period. For each well, the residual between observed and calculated heads was used to calculate RMSE. For observation well \#1, RMSE is $0.58 \mathrm{~m}$ which is very small relative to the total transient head loss (total drawdown) which was $19.7 \mathrm{~m}$ for 10 years. For observation well \#3, RMSE is $0.88 \mathrm{~m}$. The slight differences between the calculated water levels and the observed ones exist because that not all of the abstraction zones representing the pumping activity have been taken into account so far due to the data scarcity regarding their pumping amounts and duration of the wells existing in the study area. Furthermore, there are some other factors are not considered in the present simulation, such as return flows from irrigation and the groundwater inflow from the adjacent aquifers.

As described above, the variable hydraulic heads are assigned on the vertical surface of the southwest boundary for the transient simulation because of the lack of the real outflow flux there. As a simulation result, the variation of the flux from the southwest boundary is depicted in Fig. 15. The flux rises and drops seasonally but on an increasing trend. This is the result of groundwater level drop and it shows an alarming accelerated depletion of the groundwater reservoir.

\section{Conclusions and outlook}

In this work, a 3D groundwater model was developed for the Wadi Kafrein area. The basic idea of this paper was to develop and to apply a methodology in order to deal with a 


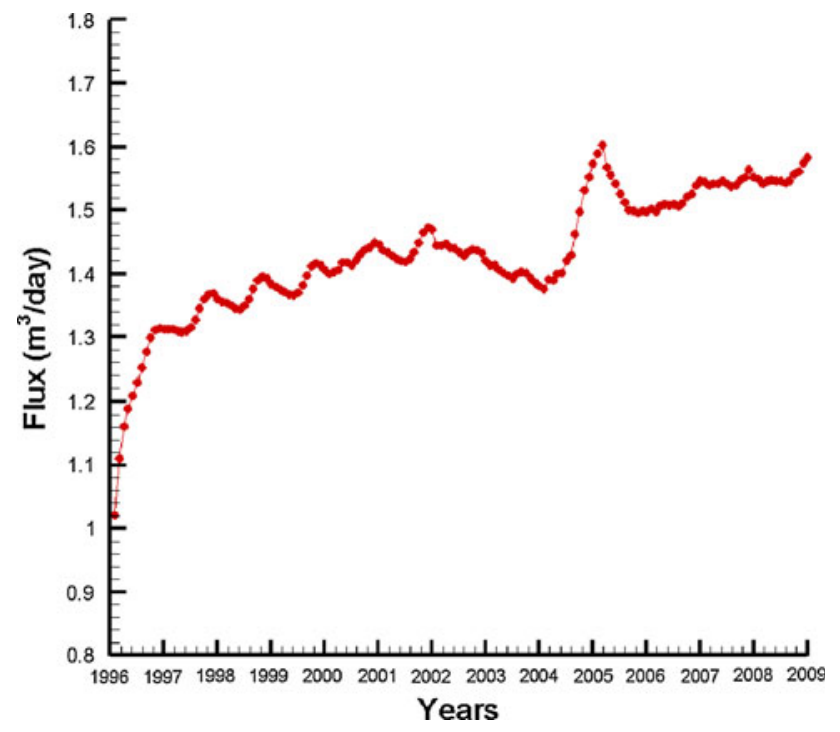

Fig. 15 Temporal variation of outflow flux at the southwest boundary

typical situation of data scarcity in hydrogeological modelling. On the one hand, high precision data are available (e.g. DEM, wellbore information, rainfall data) and can be treated in numerical models. On the other hand, we have to deal with data scarcity, i.e. data or information is only available in a few locations (observation stations) and the need to inter- and extrapolate data within the range of the catchment scale for the purpose of water resources management. The methodology is simply to start with the best possible structural geological model avoiding the limitations of many groundwater models that rely on a strict layering of formations (this is not possible for complex aquifer systems such as the Wadi Kafrein catchment). Then, more and more data are integrated into the geometric model and are approved step-by-step with available data. In the following context, the major achievements and deficiencies of this work are summarized in more details.

\section{Achievements}

The most important achievements are:

- A numerical modelling methodology was developed which can handle arbitrary hydrogeological structures such as eroded Wadies or outcropping aquifers. The basis of the complex geometric modelling is an objectoriented finite element (FE) concept which allows arbitrary combinations of finite element types in order to achieve the best possible geometric representation of the hydrogeological system. Moreover, hydrological features such as the Wadi channels are included into the FE discretization. This concept is beyond the layered approach of many groundwater models.
- The infiltration model is based on the EDK method which includes local topographical information into the data interpolation. Moreover, the finite element discretisation (see above) capturing the Wadi channels allows to include specific infiltration situations (e.g. flash floods). Regardless the assumptions (see "Deficiencies"), the infiltration model is fed by long-term data (more than 13 years).

- Due to a large number of assumptions, the groundwater model cannot be regarded as a validated. The groundwater model, however, passed a first "validation" test. Based on the long-term calibration of the groundwater model using the data from observation well \#1, the trend of groundwater level in observation well \#3 could be modeled. This can serve as a first validation step as observation well \#1 is in the downstream area close to the south-west catchment boundary whereas observation well \#3 is in the central part of the Wadi Kafrein catchment.

\section{Deficiencies}

The following deficiencies need to overcome in future work.

- The model cannot be considered as a validated groundwater model but it provides a basis for further data integration and model validation. In particular, the recharge mechanism in the Wadi Kafrein area is not completely understood so far, e.g.: Is the catchment domain properly designed? Do we have to take additional in-outflows into account? There is only a poor correlation between temporal recharge pattern and groundwater level. Concerning the groundwater recharge, the assumption was made that $20 \%$ of the precipitation are infiltrated.

- More data, e.g. from local authorities etc., such as return flows from irrigation, should be included into the model to make it more valuable for the purpose of water resources management in this area. This data acquisition needs a close cooperation with the local authorities which should be aimed at in the next project phase SMART-II.

Regardless of the deficiencies and work to be done in future, the numerical simulations show the alarming trend of groundwater level drop in this region. The present study is not just a water budget analysis. The increasing outflow fluxes from the catchment to the Dead Sea (Fig. 15) show that the groundwater level decline will be even accelerated in future.

Acknowledgments The authors would like to express their thanks to the German Ministry of Education and Research (BMBF) for supporting and funding the project: Sustainable and Integral 
Management of Available Water Resources using Innovative Technologies (SMART) under grant 02WM0802. The authors are also thankful to the funding of the Helmholtz-CSC (China Scholarship Council) Fellowships 2008. The authors are grateful of Rohini Kumar, for his help with the program support of External Drift Kriging interpolation. We would like to thank Christian Siebert and Tino Rödiger for their help in data acquisition for this work.

\section{References}

Abu-Jaber N, Ismail M (2003) Hydrogeochemical modeling of the shallow ground water in the northern Jordan Valley. Environ Geol 44:391-399

Al-Abed N, Abdulla F, Abu Khyarah A (2005) GIS-hydrological models for managing water resources in the Zarqa River basin. Environ Geol 47:405-411

Ali W, Hötzl H, Lenz S (1999) Hydrogeological study along Wadi al Kafrein, Jordan. Multinational BMBF Project "German-IsraeliJordanian-Palestinian Joint Research Project for the Sustainable Utilization of Aquifer Systems". Umwelt 2000, Halle

Ali W, Glaser J, Hötzl H, Lenz S, Salameh E, Thiel M, Werz H (2009) Groundwater conditions of the Jordan Rift escarpment northeast of the Dead Sea. In: Hötzl H, Möller P, Rosenthal E (ed), The water of the Jordan Valley-scarcity and deterioration of groundwater and its impact on the regional development, Springer, Berlin, pp 385-412

Bear J (1972) Dynamics of fluids in porous media. Dover Publications, New York

Beinhorn M, Dietrich P, Kolditz O (2005) 3-D numerical evaluation of density effects on tracer tests. J Contam Hydrol 81: 89-105

Beinhorn M, Guttman J, Sauter M, Toll M, Kolditz O (2004) Groundwater modeling of the shallow aquifer in the Jericho Area. In: 5th International Symposium on Eastern Mediterranean Geology. Thessaloniki, pp 1483-1486

Chen C, Sawarieh A, Kalbacher T, Beinhorn M, Wang W, Kolditz O (2005) A GIS based 3D Hydrosystem Model Application to the Zarqa Ma'in - Jiza areas in Central Jordan. J Environ Hydrol 13:1-13

Chua S, Bras RL (1982) Optimal estimators of mean annual precipitation in regions of orographic influence. $\mathrm{J}$ Hydrol 57:23-48

Freeze RA, Cherry JA (1979) Groundwater. Prentice Hall, New Jersey

Guttman J (2000) Hydrogeology of the eastern aquifer in the Judea Hills and Jordan Valley. Multi-Lateral Project 02WT9719, Sub Project B, Final Report, Mekorot Report No.468, pp 1-87

Guttman J (2009) Hydrogeology. In: Hötzl H, Möller P, Rosenthal E (eds), The water of the Jordan Valley - scarcity and deterioration of groundwater and its impact on the regional development. Springer, Berlin, pp 55-73

Guttman J, Salameh E, Rosenthal E, Tamimi AR, Flexer A (2009) Sustainable management of groundwater resources. In: Hötzl H, Möller P, Rosenthal E (ed), The water of the Jordan Valleyscarcity and deterioration of groundwater and its impact on the regional development, Springer, Berlin, pp 473-480

Hötzl H, Möller P, Rosenthal E (ed) (2009) The water of the Jordan Valley - scarcity and deterioration of groundwater and its impact on the regional development. Springer, Berlin

Huang JQ, Christ JA, Goltz MN (2008) An assembly model for simulation of large-scale ground water flow and transport. Ground Water 46: 882-892

Istok JD (1989) Groundwater modeling by the finite element method. American Geophysical Union, Washington
Kalbacher T, Wang W, McDermott C, Kolditz O, Taniguchi T (2005) Development and application of a CAD interface for fractured rock. Environ Geol 47:1017-1027

Khayat S, Moller P, Geyer S, Marai A, Siebert C, Abu Hilo F (2009) Hydrochemical variation in the springs water between Jerusalem-Ramallah Mountains and Jericho Fault, Palestine. Environ Geol 57:1739-1751

Kolditz O, Delfs JO, Bürger CM, Beinhorn M, Park CH (2008) Numerical analysis of coupled hydrosystems based on an objectoriented compartment approach. J Hydroinformat 10:227-244

Kolditz O, Diersch HJ (1993) Quasi steady-state strategy for numerical simulation of geothermal circulation processes in hot dry rock fracture. Int J Nonlinear Mech 28:467-481

Köppen W (1931) Grundriss der Klimakunde. Walter de Gruyter, Berlin, $388 \mathrm{p}$

Margane A, Hobler M, Almomani M, Subah A (2002) Contributions to the hydrogeology of northern and central Jordan. Geologisches Jahrbuch-Reihe C, Heft 68, Bundesanstalt für Geowissenschaften und Rohstoffe, Hannover

Miles B, Kalbacher T, Kolditz O, Chen C, Gronewold J, Wang W, Peter A (2007) Development and parameterisation of a complex hydrogeological model based on high-resolution direct-push data. Environ Geol 52:1399-1412

Odeh T, Salameh E, Schirmer M, Strauch G (2009) Structural control of groundwater flow regimes and groundwater chemistry along the lower reaches of the Zerka River, West Jordan, using remote sensing, GIS, and field methods. Environ Geol 58:1797-1810

Pardo-Iquzquiza E (1998) Comparison of geostatistical methods for estimating the areal average climatological rainfall mean using data on precipitation and topography. Int J Climatol 18:10311047

Park CH, Beyer C, Bauer S, Kolditz O (2008) Using global nodebased velocity in random walk particle tracking in variably saturated porous media: application to contaminant leaching from road constructions. Environ Geol 55: 1755-1766

Phillips DL, Dolph J, Marks D (1992) A comparison of geostatistical procedures for spatial analysis of precipitation in mountainous terrain. Agric For Meteorol 58:119-141

Rodiger T, Sauter M, Buchel G (2009) Infiltration and groundwater flow into a fractured porous sandstone aquifer in the eastern Thuringian Basin. Grundwasser 14:21-32

Salameh E (2008) Over-exploitation of groundwater resources and their environmental and socio-economic implications: the case of Jordan. Water Int 33:55-68

Salameh E, Bannayan H (1993). Water resources of Jordan, present status and future potentials. Friedrich Ebert Stiftung, Amman

Salameh E, Hammouri R (2008) Sources of groundwater salinity along the flow path, Disi-Dead Sea/Jordan. Environ Geol 55:1039-1053

Salzgitter Consult GmbH, Jordanian Consulting Engineer (JCE) Co. (1993). Raising Kafrein Dam project-site investigations reports. Ministry of Water and Irrigation MWI and Jordan Valley Authority JVA, Amman

Samaniego L, Bárdossy A, Kumar R (2009) Streamflow prediction in ungauged catchments using a copula-based dissimilarity measures. Water Resour Res. doi:10.1029/2008WR007695

Segol G, Pinder GF, Gray WG (1975) A Galerkin finite element technique for calculating the transient position of the saltwater front. Water Resour Res 11:343-347

Shawabkeh KF (2001) Geological map of Al Karama-3153-IV, 1:50.000, The Hashemite Kingdom of Jordan. Natural Resources Authority, Geology Directorate

Siebert C, Moller P, Geyer S, Berger D (2005) The dynamic hydrochemical environment of Lake Tiberias, Israel. Geochimi Et Cosmochim Acta 69: A424 
Ta'any RA, Tahboub AB, Saffarini GA (2009) Geostatistical analysis of spatiotemporal variability of groundwater level fluctuations in Amman-Zarqa basin, Jordan: a case study. Environ Geol 57:525-535

Toll M (2007) An integrated approach for the investigation of unconsolidated aquifers in a brackish environment-a case study on the Jordanian side of the lower Jordan Valley. Dissertation, University of Göttingen

Toll M (2008) Investigating unconsolidated aquifers in an arid environment - a case study from the lower Jordan Valley/Jordan. In: Zereini $\mathrm{F}$ and Hötzl $\mathrm{H}$ (eds) Climatic changes and water resources in the Middle East and North Africa, Springer, Berlin, pp 289-324

Toll M, Wu Y, Wang W, Kolditz O, Sauter M (2009) Groundwater resources in Western Jordan: a hydrogeological investigation of the influence of complex geological features on groundwater flow paths and storage. In: European Water Resources Association's (EWRA) 7th International Conference. Limassol, pp 1001-1008

Wang SQ, Shao JL, Song XF, Zhang YB, Huo ZB, Zhou XY (2008) Application of MODFLOW and geographic information system to groundwater flow simulation in North China Plain, China. Environ Geol 55:1449-1462

Wang WQ, Kosakowski G, Kolditz O (2009) A parallel finite element scheme for thermo-hydro-mechanical (THM) coupled problems in porous media. Comput Geosci 35:1631-1641

Werz H (2006) The use of remote sensing imagery for groundwater risk intensity mapping in the Wadi Shueib, Jordan. Dissertation, Karlsruhe University

Werz H, Hötzl H (2007) Groundwater risk intensity mapping in semiarid regions using optical remote sensing data as an additional tool. Hydrogeol J 15:1031-1049 